\title{
Experimental Evaluation of the Influence of Overheating on the Properties of Metal During its Processing on Metal- cutting Machines for Subsequent use in Aeronautics
}

\author{
${ }^{1}$ Shehret Tilvaldyev, ${ }^{2}$ Julio César Cuéllar Mata, ${ }^{3}$ Manuel Alejandro Lira Martinez, ${ }^{4}$ Jose Omar Davalos Ramirez \\ ${ }^{1,2,3,4}$ Aeronautics Department of Universidad Autónoma de Ciudad Juarez (UACJ), Mexico
}

\begin{abstract}
Heat has critical influences on machining: it can increase tool wear and then reduce tool life, cause thermal deformation and changes to physical and mechanical properties of the job material. But due to the complexity of machining mechanics, it's hard to predict the intensity and distribution of the heat sources in an individual machining operation, and many efforts in theoretical analyses and experiments have been made to understand this phenomenon, but some problems are still unsolved.

This paper reports results of Experimental researches that were performed to investigate how the heat of machining processes changes mechanical and thermal properties of the work-pieces, and how the normal and increased (overloaded) machining parameters changes heat influence and properties of material using in Aeronautics.
\end{abstract}

Keywords: Metal Cutting, Temperature in Cutting zone, Hardness property, Tensile Strength property.

\section{INTRODUCTION}

Machining is one of the most important among the manufacturing processes, and is necessary where tight tolerances on dimensions and finishes are required. Machining a material (piece cutting, chip cutting, and any other materialremoval process) causes great energy dissipation, and problems associated to the temperature field in the tool and the work-piece: heat transfer, dimensional deformations, and even material property transitions. Many researchers have explored the prediction, measurement and influences of the temperature in the area around the tool- work-piece interface under different conditions and on different types of machines [1 - 9]. These problems have been investigating since the middle of the 19th century, and one of the earliest was Frederic Winslow Taylor, who wrote his paper "On the art of cutting metals" in 1907 [10] and realized the relevance of tool-tip temperature on tool life, and invented a tungsten carbide tool-steel $(18 \% \mathrm{~W}$ $4 \% \mathrm{Cr}-1 \% \mathrm{Va}-0.75 \% \mathrm{C})$ that kept sharp even hot-red without refrigeration. But the American-born British engineer Benjamin Thompson (later Count Rumford of Bavaria) was the first, in 1798 , to study thermal effects on iron machining (making cannons by boring cylinders of iron immersed in water).

Grinding is an important machining process that uses bonded abrasives to remove surface material, and can lead to residual stress in the near-surface layers of the remaining work-piece. In grinding, most of the consumed power is transformed into heat, thereby generating possible high temperatures in the contact zone between the wheel and workpiece [11-13]. The high temperatures at the wheel-workpiece interface may cause thermal damages to the work-piece material [14-17]. In order to analyze the effects of various grinding parameters on the temperatures generated at the contact zone, many previous studies have been conducted in an attempt to establishing a theoretical model to cover temperature characteristics in grinding with wheels of continuous structure.

King and Hahn [18] were the earliest authors who have discussed the influence of wheel speed on grinding power and have determined experimentally that very low or very high wheel speed may require high grinding power. Their results show that optimum wheel speed in most cases is in the range of 8000-10,000 RPM; at higher or lower speeds, thermal damage is more likely to occur.

Nowadays, thermal analyses of grinding processes are usually based on Carslaw and Jaeger's early work of a sliding heat source model [19-20]. In Carslaw and Jaeger's model, a heat source moves with a constant velocity along the surface of a semi-infinite solid, under an assumed quasi-steady state heat transfer condition. Hae-Ji Kim et al [21] presented that the scalene triangle model was particularly suitable for estimating the work-piece temperature. In fact, both theoretical and experimental studies [22-24] have shown that the heat generated in grinding can be approximated reasonably by a scalene triangular heat flux which moves along the positive direction of $\mathrm{x}$-axis on the work-piece surface.

Malkin et al [25] provided a comprehensive overview of thermal analyses for grinding processes and the effect of grinding temperatures on thermal damage to the work-piece. Thermal models have been developed which take the most 
important factors into account: depths of cut, work-piece velocities, and energy partition to the work-piece that can vary significantly depending of the type of grinding, abrasive grain material, and grinding fluid. An example of energy partition of $65 \%$ obtained by matching the maximum temperature distributions at various depths to the analytically computed temperature is shown by Gao et al [24] for grinding of AISI 1020 steel work-piece with aluminum oxide wheel, triangular heat source and time constant $=4.3 \mathrm{msec}$. Some differences between Theoretical and Experimental measured values may be attributed to the Second Low of Thermodynamics: the thermal model assumes that all the $100 \%$ energy expended by grinding is converted to heat, however it has been shown that about $3-10 \%$ of the energy expended by plastic deformation may not be converted to heat [26].

Excessive grinding temperatures cause thermal damage to the work-piece, for example, the heat of grinding a hardened steel without any burning, generally induced some softening due to tempering close to the surface [27-29]. Starting with an initial hardness of about $8 \mathrm{GPa}$, a greater degree of tempering can be seen with increasing wheel depth of cut due to higher temperatures to a greater depth below the surface. Rehardening of the steel work-piece also occurs towards the surface at the biggest depth of cut.

Temperature measuring methods do not provide a practical means to identify and control grinding temperatures in a production environment, as their use is generally restricted to the laboratory. Much more feasible approach to estimate grinding temperatures can be provided when realtime monitoring of the grinding power coupled with a thermal analysis of the grinding process.

Nowadays, grinding temperatures can be predicted quite well, but how the grinding temperatures affect the work-piece surface is not well understood. In general, when cutting temperatures raises too high, tool wear increases and damage can be caused to the work-piece and stresses can build up in the finished item. Also, it has been shown that work surface integrity and the machining precision are all directly affected by cutting temperature.

It is well known, that products of aerospace industry are relatively expensive and that the manufacturers will have to reduce their expenses to survive in tense economical environment, and new frontier in aerospace engineering technology will be the cost. Because the manufacturing cost of a typical civil aircraft is about $30 \%$ of its life cycle cost [30], there is some potential to reduce production expenses through innovations, and anything that will improve machining productivity is a cost saver. For maximum productivity and decreasing the cost, metal removal rate must be as high as can be achieved in a given set of circumstances. In order to remove as much material as possible in a short time as possible, the cutting process must be as fast as it achievable.

Temperature is one of the limiting factors in this process. Thermo-physical futures of (solid) materials usually refer to transport properties, while Thermodynamic refers to equilibrium properties. The thermal shock related to thermal expansion - the stress caused by non-uniform thermal expansions/contractions. The main interest here is on mechanical properties of materials, so that other thermophysical properties relevant to other fields of Physics are not considered.

\section{MATERIAL, METHODS AND EXPERIMENTAL PROCEDURES}

In this work, the experimental procedures were used to obtain information (results) and investigate:

a) how the heat of surface grinding processes with standard (normal) parameters changes Hardness and Tensile strength properties of the work-pieces, and how the increased (overloaded) grinding parameters (Cutting velocity, Depth of cut, and the Material Removal Rate) changes heat influence and properties of material; and

b) how the heat of machining processes with standard (normal) parameters changes physical and mechanical properties of the work-pieces, and how the increased (overloaded) machining parameters (high RPM, Feeding speed and Depth of cut) changes heat influence and properties of material.

\subsection{Material}

One type of work-piece material for all grinding processes (the same initial physical and mechanical properties) was used - B1112 Steel, with 160 BHN hardness parameter, and $100 \%$ Machinability Rating. For the experiments was prepared one $150 \mathrm{~mm} \times 40 \mathrm{~mm} \times 25 \mathrm{~mm}$ reference item, and 21 the same dimension pieces of steel to grind (or machining) on different machining parameters.

\subsection{Machining Equipment}

Material removing process completed on Grinding (Hurco TM8) Machine with following variables: Depth of cut (d), $\mathrm{mm}$, Work-piece speed $(\mathrm{Vw}), \mathrm{m} / \mathrm{min}$, Wheel Speed (Vs), $\mathrm{m} / \mathrm{sec}$, and Specific Material Removal Rate (Qw), $\mathrm{mm} 3 / \mathrm{mm}$.sec. Machining processes were completed by grinding wheel with Aluminum Oxide (A12O3) abrasive material, Table 1. 
Table 1: Properties of grinding wheel's Abrasive material

\begin{tabular}{|l|l|}
\hline Parameters & Aluminum Oxide $\left(\mathrm{Al}_{2} \mathrm{O}_{3}\right)$ \\
\hline Crystal Structure & Hexagonal \\
\hline Density, $\left(\mathrm{g} / \mathrm{cm}^{3}\right)$ & 3.98 \\
\hline Melting point, $\left({ }^{\circ} \mathrm{C}\right)$ & 2040 \\
\hline Knoop Hardness, $\left(\mathrm{kg} / \mathrm{mm}^{2}\right)$ & 2100 \\
\hline
\end{tabular}

Also Material removing process completed on Manual Lathe (Hurco TM8) Machine and Manual Milling Machine with following variables: Revolution per minute (RPM), Feeding speed (mm/rev), and Depth of cutting $(\mathrm{mm})$.

\subsection{Temperature Measurement}

There are no simple reliable methods of measuring the temperature field. In this experiment temperature measured in the real machining process directly by means of temperature paints techniques, and indirectly by measuring the infrared radiation (FLIR 5). Remote measuring/inverse methods (FLIR 5) does not provide easy to read temperatures at the point of interest, where the cutter is in contact with the work-piece, but produces a temperature map, showing areas of similar temperature. Objects are shown in different colors to illustrate the different temperature zones.

\subsection{Material Properties Testing Equipment}

Brinell hardness Test machine was used in attempt to examine the relation of the deformation of metal specimen to the hardness property of a metal. The specimen was mounted unto the machine and the machine was loaded with equivalent loads as indicated by the experimental procedure. The results were measured by help of a microscope, recoded, and tabulated.

WAW Computer-control electro-hydraulic servo universal testing machine (with maximum test force $1000 \mathrm{KN}$ ) was used to perform Tensile Strength tests of the initial (reference) and machined at very high (overloaded) parameters specimens.

\subsection{Experimental Procedures}

First, (for the Surface Grinder) we prepared material - one piece of B112 Steel as a reference (initial) specimen, and 28 same dimension pieces for the machining at different (from min to max) parameters of grinding processes. Fig. 1 showing the geometry of Surface Grinding and the cutting condition variables.
https://doi.org/10.47001/IRJIET/2020.411001

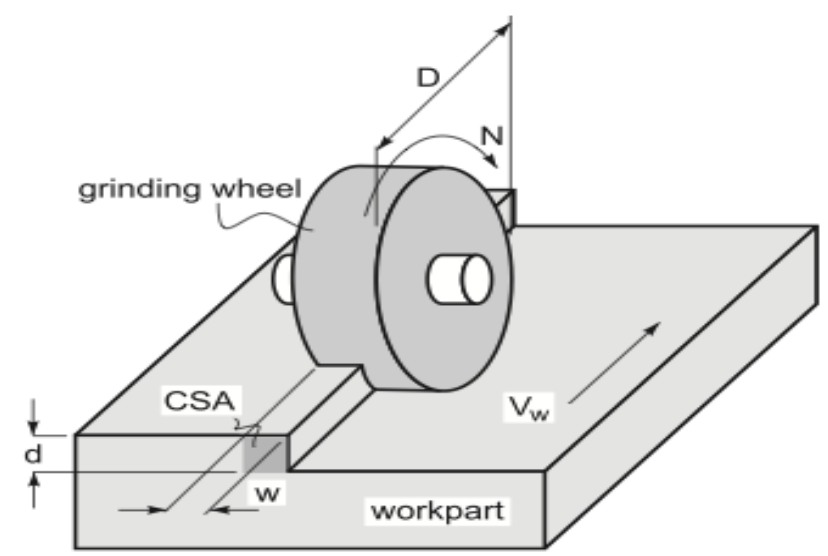

Figure 1: Surface grinding geometry and cutting conditions

The cutting velocity $V_{s}$ in grinding is very high. It is related to the rotational speed of the wheel by

$$
\mathrm{V}_{\mathrm{s}}=\pi \mathrm{DN}
$$

Where (D) is the wheel diameter and (N) is the rotational speed of the grinding wheel. Depth of cut (d) is called in feed and is defined as the distance between the machined and work surface. As the operation proceeds, the grinding wheel is fed laterally across the work surface on each pass by the workpiece. The distance at which the wheel is fed is crossfeed, and is actually the width of cut (W). The crossfeed multiplied by infeed determines the cross-sectional area of cut, CSA: CSA $=$ crossfeed $\times$ infeed $=\mathrm{W} \times \mathrm{d}$. The cross-sectional area in grinding is relatively small compared to other traditional machining operations. The work-piece moves past the wheel at a certain linear velocity called a feed $(\mathrm{Vw})$. The material removal rate, $(\mathrm{Qw})$, is defined by $\mathrm{Qw}=\mathrm{VwCSA}$. Table 2 showing experimental processes matrix and grinding variables.

Table 2: Grinding Process Variables

\begin{tabular}{|l|c|c|c|}
\hline Machine Settings & $\begin{array}{c}\text { Grinding } \\
\text { Approach I }\end{array}$ & $\begin{array}{c}\text { Grinding } \\
\text { Approach II }\end{array}$ & $\begin{array}{c}\text { Grinding } \\
\text { Approach III }\end{array}$ \\
\hline $\begin{array}{l}\text { Depth of cut (d), } \\
\mathrm{mm}\end{array}$ & $0.05-0.1$ & $0.1-1.5$ & $1.5-3.0$ \\
\hline $\begin{array}{l}\text { Work-piece speed } \\
(\mathrm{Vw}), \mathrm{m} / \mathrm{min}\end{array}$ & $1-30$ & $1-30$ & $1-30$ \\
\hline $\begin{array}{l}\text { Wheel Speed } \\
(\mathrm{Vs}), \mathrm{m} / \mathrm{sec}\end{array}$ & $20-60$ & $20-60$ & $20-60$ \\
\hline $\begin{array}{l}\text { Specific Material } \\
\text { Removal Rate } \\
(\mathrm{Qw}), \\
\mathrm{mm} \text { \% } / \mathrm{mm} . \mathrm{sec}\end{array}$ & $0.1-10$ & $10-45$ & $10-60$ \\
\hline
\end{tabular}


Next, the temperature controlled equipment and materials were prepared to measure (directly and indirectly) the heat distribution during the cutting processes. Than metal removing (grinding) process were performed and taken temperature measurements. Finished work-piece cooled down at room temperature. We repeated this process for the other specimens, each time increasing machining parameters according the experiment matrix (Table 2). For each machining process used well dressed grinding wheel. Finally, we used SEM (scanning electron microscopy) to investigate any structural changes and Brinell hardness Test machine to test the reference specimen and machined items to examine the properties of a metal, and analyzed collected data.

For the machining on Manual Lather (Hurco TMS), we prepared material - one piece of $200 \mathrm{~mm}$ long and $25 \mathrm{~mm}$ in diameter B112 hot rolled steel as a reference (initial) specimen, and 40 same dimension pieces for the machining at different (from min to max) parameters of cutting processes on Lathe and Milling machines. Next, the temperature controlled equipment and materials were prepared to measure (directly and indirectly) the heat distribution during the cutting processes. Then metal removing (cutting) process was performed and taken temperature measurements, and finished work-piece cooled down at room temperature. We repeated this process for the other specimens, each time increasing machining parameters. For each machining process used brand new cutting tool to designate heat influences to the cutter. Finally, we used Brinell hardness Test machine to test the reference specimen and machined items to examine the properties of a metal, and analyzed collected data.

\section{RESULTS AND DISCUSSIONS}

\subsection{Surface Grinding Results and Discussion}

Even though we are studying how the heat changes mechanical properties of the finished wok-piece, and not investigating the heat dynamics in grinding zone process, is necessary to discuss the most important approximations of the heat interference in tool-cheep-workpiece area. The heat problem is not so serious in traditional grinding helped with cooling fluids, but may be important when increasing productivity, in high precision work, and when the use of cooling fluids is not appropriate. In grinding, nearly all of dissipated energy is converted into heat that in turn raises the temperature in the machining zone. According to the Thermodynamics 2-nd Low the heat flows spontaneously from a hot area to a cool one, and heat in grinding zone dissipated in: a) cheep-tool-workpiece unit, and depends of thermal conductivity of the items; b) solids (cutting zone) and environment. The heat generated is shared by the chip, cutting tool and the blank. The apportionment of sharing that heat depends upon the configuration, size and thermal conductivity of the tool-work material and the grinding condition. After several minutes up to one hour, depending on size of finished work-piece, heat ultimately will flow to the environment. The amount of energy stored elastically in the solids is negligible. The maximum temperature at grinding surface significantly increases with increasing of Grinding Depth (d), mm Fig. 2, and speed (Vw) of Work-piece, Fig. 3.

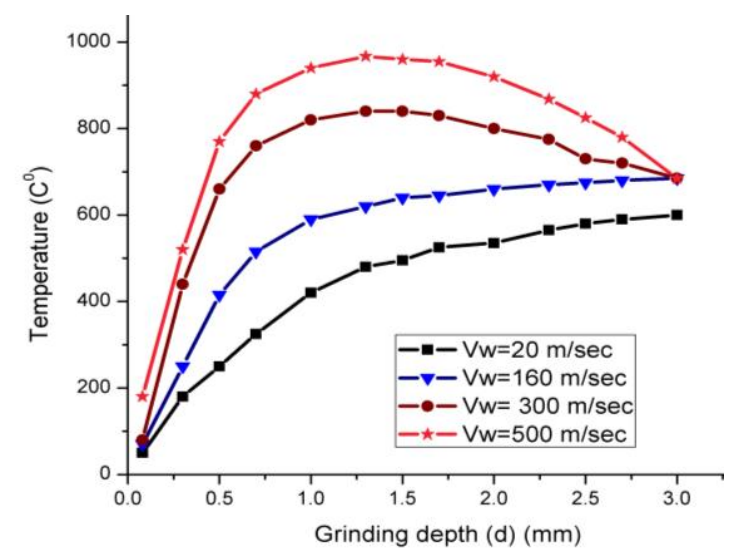

Figure 2: Maximum temperature $\left({ }^{\circ} \mathrm{C}\right)$ versus Grinding depth $(\mathrm{d}), \mathbf{m m}$, at four different Work-piece speed (Vw), m/min

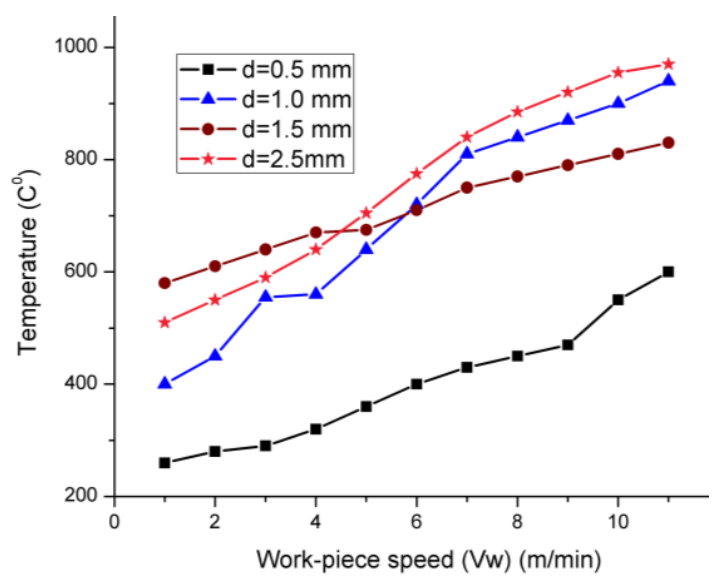

Figure 3: Maximum temperature $\left({ }^{\circ} \mathrm{C}\right)$ versus Work-piece speed $(\mathrm{Vw})$, m.min, for different cutting depths (d), mm

It is observed (Fig.2), that the heat in grinding zone significantly rises from room temperature to $800^{\circ} \mathrm{C}$, when grinding depth (d) increases up to $0.5 \mathrm{~mm}$ for work-piece machined at speed ( Vw) $500 \mathrm{~mm} / \mathrm{sec}$; to $6700 \mathrm{C}$ at work-piece speed $300 \mathrm{~mm} / \mathrm{sec}$, than intense of temperature's dynamics lowers to $800^{\circ}-950^{\circ} \mathrm{C}$, when grinding depth (d) rises to 1.2 $\mathrm{mm}$, and further does not increases, even though the grinding depth extents to $3.0 \mathrm{~mm}$. The temperature does not rises at high grinding depth (d) and work-piece speed ( $\mathrm{Vw})$, because great amount of heat dissipated with very fast forming and removing chips, preventing diffusion of the heat in work-piece and grinding wheel. Heat generation and surface temperatures in grinding zone are highly depended on grinding depth (d), 
because cutting interface area increases when grinding depth extends. Results of the experiments (Fig.3) show, that the temperature at grinding surface does not significantly depends on work-piece speed $(\mathrm{Vw})$ : when speed increases 10 times, the temperature in machining zone rises maximum 2.15 times for all variation of depth (d).

Hardness is the property of a material (metal) by virtue of its ability to resist abrasion, indentation (or penetration) and scratching by harder bodies. It is the resistance of a material to permanent deformation of the surface. In other words, one can define it as the resistance of the metal to penetration by an indenter. The hardness of a surface of the material is, of course, a direct result of inter-atomic forces acting on the surface of the Material. We must note that hardness is not a fundamental property of a material, however, but rather a combined effect of compressive, elastic and plastic properties relative to the mode of penetration, shape of penetrator, etc. Hardness seems to bear a fairly constant relationship to the tensile strength of a given material and thus it can be used as a practical non-destructive test for an approximate idea of the value of that property and the state of the metal near the surface. All hardness tests are made by penetration a hardened steel ball into the testing surface, and Brinell Hardness Test machine was used in attempt to examine the relation of the deformation to the hardness property of a metal. The specimen was mounted unto the machine and the machine was loaded with equivalent loads as indicated by the experimental procedure. The results were used to plot graphical curves and presented in Fig. 4.

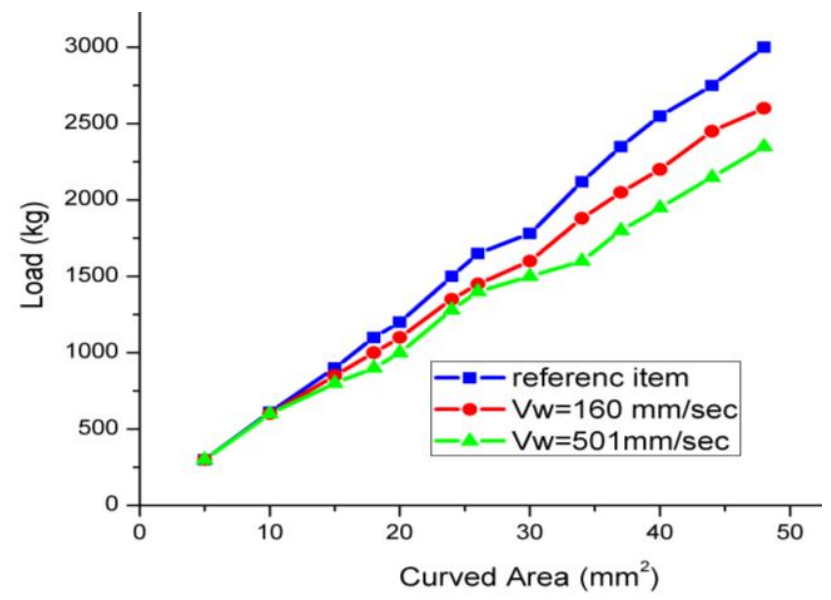

Figure 4: Hardiness diagrams for Reference and Grinded B112 steel at Work-piece speed Vw $=160 \mathrm{~mm} / \mathrm{sec}$, and $500 \mathrm{~mm} / \mathrm{sec}$

Series tests was made for all 22 items, but diagrams in Fig. 4 shows results only for three of them: reference (initial) specimen; work-piece, that was machined on the highest parameters, inducing the maximum temperature in machining zone (Grinding Depth $-1.35 \mathrm{~mm}$ and work-piece speed - 500 $\mathrm{mm} / \mathrm{sec}$ ); and work-piece grinded at $160 \mathrm{~mm} / \mathrm{sec}$ speed and
$3 \mathrm{~mm}$ depth. The data for the rest 19 tested items positioned in between presented on the graph two polar (minimum and maximum) lines. The graph shows, that Curved Area on the tested surfaces of the reference and machined items does not have noticeable difference under the application of Load up to $1000 \mathrm{~kg}$, and this difference less than $2 \mathrm{~mm} 2$. Significant difference $\left(8 \mathrm{~mm}^{2}\right)$ in deforming surface areas appears, when applied Load equal $2600 \mathrm{~kg}$. Maximum Curved Area (48 $\mathrm{mm}^{2}$ ) forms under the Load of 2300 and $2600 \mathrm{~kg}$ for the machined work-pieces, and $3000 \mathrm{~kg}$ - for the reference (initial) steel. So, we can state, that hardness property of the testing steel degrades if the heat induced by grinding process increases temperature in cutting zone more than $8500 \mathrm{C}$.

Hardness is the state of the metal near the surface, and we consider it as a surface property. We performed in laboratory Tensile Strength tests to analyze how the thermal stress in work-piece, induced by heat in grinding zone, affect on volume property of the steel. For the test were prepared two specimens: one - from reference item and another - from grinded at higher machining parameters work-piece. Diagram in Fig. 5 shows Tensile Strength test results for the two items: reference (initial) steel and finished work-pieces, heated during the machined process up to $8500-9800 \mathrm{C}$, and cooled down in room environment. Stress, under the application of pressure up to $440 \mathrm{MPa}$, does not induce any deformation in testing items. Strain appears, and makes significant deformation of testing elements, when stress rises close to 600 MPa, but dynamics and character of the Strain deformations for both of testing specimens the same and almost identical.

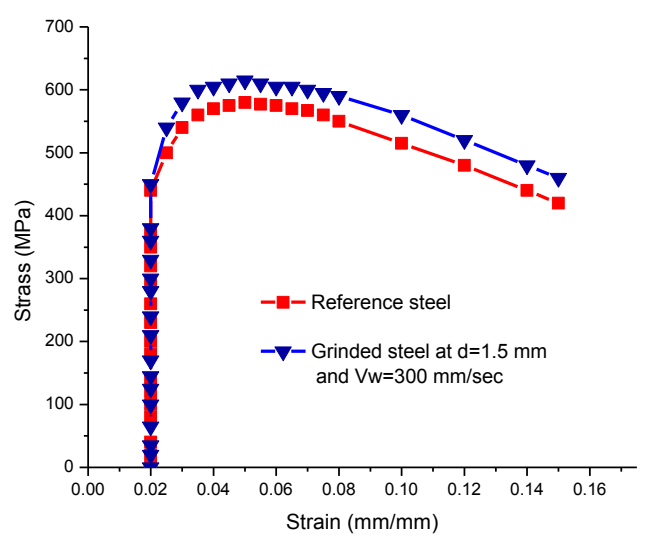

Figure 5: Stress - Strain diagram for Reference and Machined B112 steel (Grinding Deep d = $1.5 \mathrm{~mm}$, and Work-piece speed Vw $=300 \mathrm{~mm} / \mathrm{sec}$ )

The thermal stress from high temperature in grinding zone (up to $950^{\circ} \mathrm{C}$ ) does not make any significant changes in Tensile Strength property of testing steel at given dimensions. Difference in Stress-Strain diagram related to the difference in dimensions of reference and machined specimens $(3 \mathrm{~mm})$, 
ISSN (online): 2581-3048

made by grinding process. Most likely, decreasing the dimension of the specimen, for the same type of steel (with same thermal conductivity), increases probability and amount of Strain deformation, but that is the subject of additional study.

\subsection{Manual Lather's Machining Results and Discussion}

The heat problem is not so serious in traditional machining helped with cutting fluids, but may be important when increasing productivity, in high precision work, and when the use of cutting fluids is not appropriate. In cutting, nearly all of energy dissipated in plastic deformation is converted into heat that in turn raises the temperature in the cutting zone. Since the heat generation is closely related to the plastic deformation and friction, has been specified [3, 9, 11] three main sources of heat in cutting process: Plastic deformation by shearing in the Primary shear zone; Plastic deformation by shearing and friction on the cutting face (Secondary Shear Zone); Friction between work-piece and tool on the tool flank (Friction on work-piece). Cutting temperature is not constant through the tool, chip and workpiece.

Even though we are studying how the heat changes mechanical properties of the finished wok-piece, and not investigating the heat dynamics in cutting process, it is necessary to discuss the most important approximations of the heat interference in tool-cheep-workpiece area. The cutting power is the cutting force $(\mathrm{F})$ times the cutting speed $(\mathrm{V})$ (the moment times the angular speed in rotating machines):

$$
\mathrm{W}=\mathrm{FV}=\mathrm{kVA}=\mathrm{Q}_{1}+\mathrm{Q}_{2}+\mathrm{Q}_{3} \approx \sigma_{\text {break }} \mathrm{VA},
$$

Where, $\mathrm{k}$ - specific force of cutting $\mathrm{k}=\mathrm{F} /(\mathrm{hw}) ; \mathrm{Q} 1$ - sours of heat by shearing in primary shear zone; Q2 - sours of heat by shearing and friction on the cutting face; Q3 - heat from friction between chip and tool on the tool flank; $\sigma$ - breaking pressure (perpendicular to the cutting plane and against the piece); $A$ - area of contact in tool-piece cutting zone $(A=h w)$, $\mathrm{mm} 2 ; \mathrm{h}$ - nominal depth of cut; w - width of cut.

Typical values of the power contribution may be $60 \%$ for plastic deformation and breaking, 30\% for chip-tool friction at the rake and $10 \%$ for piece-tool friction at the flank, and all this work degrades to thermal energy (equivalent heat). According to the Thermodynamics 2-nd Law the heat flows spontaneously from a hot area to a cool one, and heat in cutting zone dissipated in: a) cheep-tool-workpiece unit, and depends of thermal conductivity of the items; b) solids (cutting zone) and the environment. The heat generated is shared by the chip, cutting tool and the blank. The apportionment of sharing that heat depends upon the configuration, size and thermal conductivity of the tool-work material and the cutting condition. After several minutes up to one hour, depending on size of finished work-piece, heat ultimately will flow to the environment. The amount of energy stored elastically in the solids is negligible. The temperature in metal cutting significantly increases with increasing some cutting conditions - Cutting speed $(\mathrm{m} / \mathrm{min})$ and Feed $(\mathrm{mm} / \mathrm{rev})$, Figure 6, but does not relatively changes with increasing the depth of cut, Figure 7.
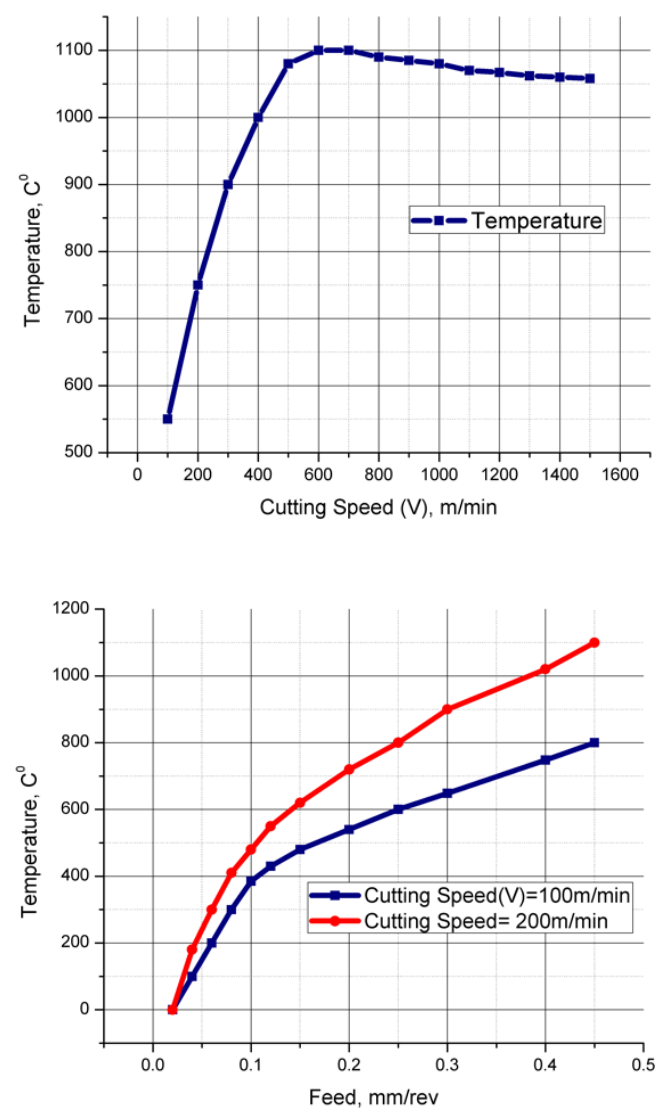

Figure 6: Cutting temperature as a function of Cutting Speed V (m/min) and Feed $(\mathrm{mm} / \mathrm{rev})$

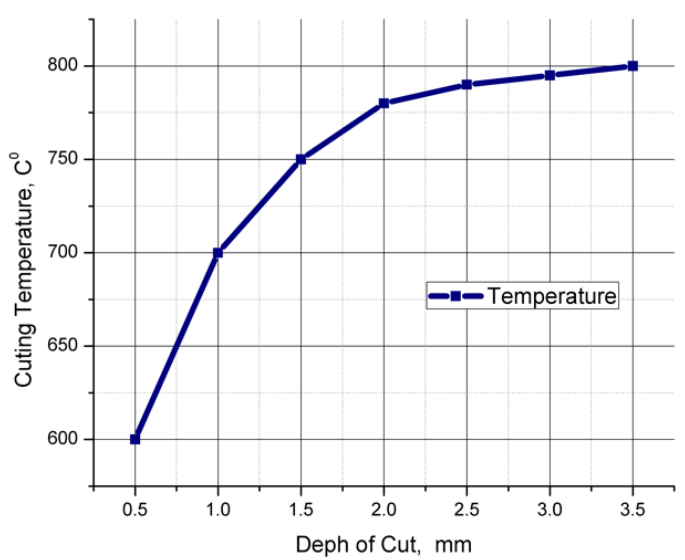

Figure 7: Cutting temperature as a function of Cutting Depth 
It is observed, that the maximum temperature is developed not on the very cutting edge, but at the tool rake some distance away from the cutting edge (some $800^{\circ} \mathrm{C}$ have been measured at Cutting Speed $100 \mathrm{~m} / \mathrm{min}$ and Feed 0.45 $\mathrm{mm} / \mathrm{rev}$, and up to $1090^{\circ} \mathrm{C}$ on rough chipping at $200 \mathrm{~m} / \mathrm{min}$ with the same amount of Feed $-0.45 \mathrm{~mm} / \mathrm{rev})$. Cutting heat significantly rises from room temperature to $800^{\circ} \mathrm{C}$, when cutting speed (V) increases up to $250 \mathrm{~m} / \mathrm{min}$, than lowers intense of temperature's dynamics $\left(800^{\circ}\right.$ to $\left.1000^{\circ} \mathrm{C}\right)$, when cutting speed $(\mathrm{V})$ rises to $500 \mathrm{~m} / \mathrm{min}$, and further does not increases, even though the cutting speed extents to 1500 $\mathrm{m} / \mathrm{min}$. The temperature does not rises at very high cutting speed $(\mathrm{V}=600-1500 \mathrm{~m} / \mathrm{min})$, because great amount of heat dissipated with very fast forming and removing chip, preventing diffusion of the heat in tool and work-piece.

Heat generation and temperatures in the primary and secondary zones are highly depended on the cutting conditions (the Feed of cutting tool and RPM of the work-piece for lathe, and RPM of the cutting tool for Mill machines), while heat generation the flank zone is strongly influenced by tool - flank wear. The Cutting temperature, as mentioned above, is not proportional to Cutting Depth, because there is the same cutting interface area for any Depth, and only the 'wall effect' counts. Results of the experiments in Figure 6 show, that if Cutting Depth increases 7 times, the Cutting temperature rises only 1.3 times.

Hardness is the property of a material (metal) by virtue of its ability to resist abrasion, indentation (or penetration) and scratching by harder bodies. It is the resistance of a material to permanent deformation of the surface. In other words, one can define it as the resistance of the metal to penetration by an indenter. The hardness of a surface of the material is, of course, a direct result of inter-atomic forces acting on the surface of the material. We must note that hardness is not a fundamental property of a material, however, but rather a combined effect of compressive, elastic and plastic properties relative to the mode of penetration, shape of penetrator, etc. Hardness seems to bear a fairly constant relationship to the tensile strength of a given material and thus it can be used as a practical non-destructive test for an approximate idea of the value of that property and the state of the metal near the surface. All hardness tests are made by penetrating a hardened steel ball into the testing surface, and Brinell Hardness Test machine was used in attempt to examine the relation of the deformation to the hardness property of a metal. The specimen was mounted into the machine and the machine was loaded with equivalent loads as indicated by the experimental procedure. The results were used to plot graphical curves and presented in Figure 8.

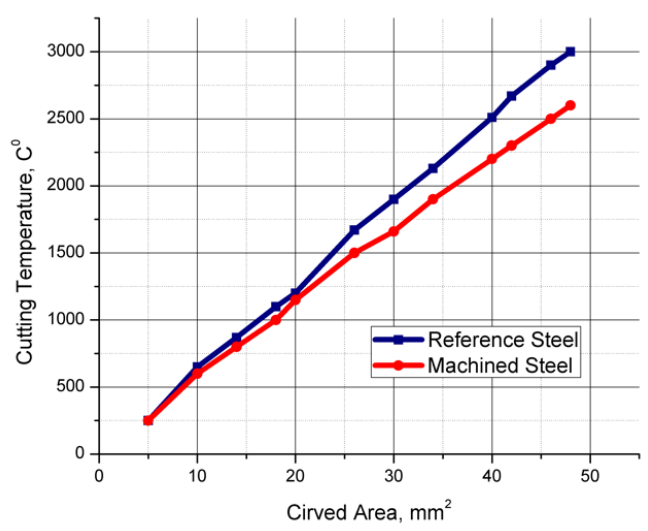

Figure 8: Hardiness diagrams for Reference and Machined B112 steel

Series tests were made for all 41 items, but diagrams in Figure 4 shows results only for two of them: (a) reference (initial) specimen; and (b) work-piece, that was machined on the highest parameters, inducing the maximum temperature in the Cutting zone (Cutting Speed $-1500 \mathrm{~m} / \mathrm{min}$, Feed of cutting tool $-0.45 \mathrm{~mm} / \mathrm{rev})$. The data for the 39 tested items located in between presented on the graph two polar (minimum and maximum) lines. The graph shows, that the Curved Area on the tested surfaces of the reference and machined items do not have noticeable difference under the application of Load up to $1000 \mathrm{~kg}$, and this difference is less than $2 \mathrm{~mm}^{2}$. Significant difference $\left(8 \mathrm{~mm}^{2}\right)$ in deforming surface areas appears, when the applied Load equal $2600 \mathrm{~kg}$. Maximum Curved Area (48 $\mathrm{mm}^{2}$ ) forms under the Load of $2600 \mathrm{~kg}$ for the machined work-piece, and $3000 \mathrm{~kg}$ - for the reference (initial) steel. So, we can state, that hardness property of the testing steel degrades if the heat in cutting process increases temperature in cutting zone to more than $950^{\circ} \mathrm{C}$.

Hardness is the state of the metal near the surface, and we consider it as a surface property. We performed in laboratory Tensile Strength tests to analyze how the thermal stress in work-piece, induced by heat in cutting zone, affect on volume property of the steel, and results shown in Figure 9.

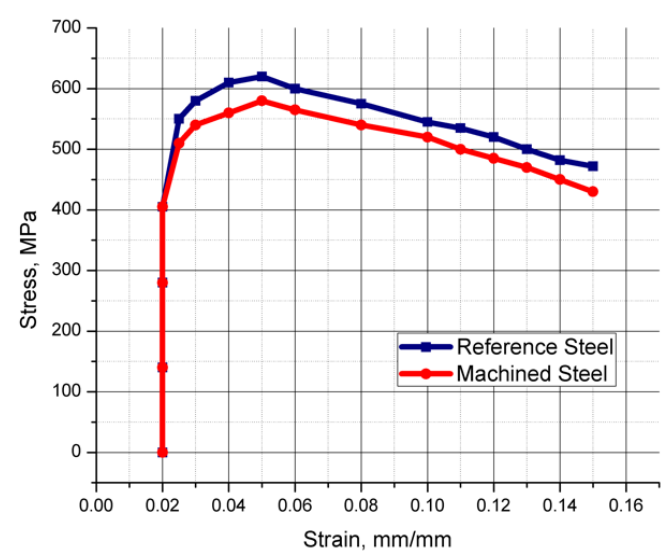

Figure 9: Stress - Strain diagram for Reference and Machined B112 steel 
The diagram shows Tensile Strength test results for the two items: reference (initial) steel and finished work-piece, heated during the machined process up to $850^{\circ}-1090^{\circ} \mathrm{C}$, and cooled down in room environment. Stress, under the application of pressure up to $560 \mathrm{MPa}$, does not increase any deformation in testing items. Strain appears, and makes significant deformation of testing elements, when stress rises close to $600 \mathrm{MPa}$, but dynamics and character of the Strain deformations for both of testing specimens the same and almost identical, (Figure6). The thermal stress from high temperature in cutting zone (up to $1090 \mathrm{C}^{0}$ ) does not make any significant changes in Tensile Strength property of testing steel at given dimensions.

Difference in Stress-Strain diagram related to the difference in diameters of reference (a) and machined (b) specimens (Cutting Depth made diameter of the item (b) for 7 $\mathrm{mm}$ less than diameter of item (a). Most likely, decreasing the diameter of the specimen, for the same type of steel (with same thermal conductivity), increases probability and amount of Strain deformation, but that is the subject of additional study.

\section{CONCLUSION}

Laboratory experiments were performed to investigate how the normal and increased (overloaded) machining parameters (Work-piece Speed (Vw), Grinding Depth (d), Cutting Speed (V), Cutting Depth (D), and Feed of tool) changes heat influence and some properties of material, and defined following:

1. The temperature in grinding zone (workpiece abrasive wheel - chip) significantly depends and increases with increasing the Grinding Depth ( $\mathrm{mm}$ ) and not much, when escalating speed of work-piece $(\mathrm{mm} / \mathrm{sec})$, but temperature does not rises more than $950^{\circ}-1000^{\circ} \mathrm{C}$ at very high machining parameters, because great amount of heat dissipated with very fast forming and removing chip, preventing diffusion of the heat in work-piece.

2. Hardness is the state of the metal near the surface (we consider it as a surface property) does not have noticeable difference for the reference and machined specimens under the application of Load up to 1000 $\mathrm{kg}$, and this difference less than $2 \mathrm{~mm} 2$ of curved area, when temperature in cutting zone was less than $800^{\circ} \mathrm{C}$. The Hardness property of the testing steel degrades if the heat in machining process increases temperature in grinding zone more than $950^{\circ} \mathrm{C}$.

3. The thermal stress induced by high temperature in grinding zone (up to $1000^{\circ} \mathrm{C}$ ) does not make any significant changes in Tensile Strength property of testing steel at given dimensions. Strain appears, and makes significant deformation of testing elements, when stress rises close to $600 \mathrm{MPa}$, but dynamics and character of the Strain deformations for both of testing specimens the same and almost identical.

4. The temperature in orthogonal metal cutting zone (workpiece - cutting tool - chip) significantly depends and increases with increasing the Cutting speed $(\mathrm{m} / \mathrm{min})$ and Feed of Cutting Tool $(\mathrm{mm} / \mathrm{rev})$, but temperature does not rises more than $1000^{\circ}-$ $1100^{\circ} \mathrm{C}$ at very high cutting speed $(\mathrm{V}=600-1200$ $\mathrm{m} / \mathrm{min}$ ), because great amount of heat dissipated with very fast forming and removing chip, preventing diffusion of the heat in tool and work-piece.

5. The Cutting temperature is not proportional to Cutting Depth and does not relatively changes with increasing the depth of cut, because there is the same cutting tool - workpiece interface area for any Depth, and only the 'wall effect' counts: Cutting Depth increased 7 times raises the temperature only 1.3 times.

6. Hardness is the state of the metal near the surface (we consider it as a surface property) does not have noticeable difference for the reference and machined specimens under the application of Load up to 1000 $\mathrm{kg}$, and this difference less than $2 \mathrm{~mm}^{2}$, when temperature in cutting zone was less than $800^{\circ} \mathrm{C}$. The Hardness property of the testing steel degrades if the heat in cutting process increases temperature in cutting zone more than $950^{\circ} \mathrm{C}$.

7. The thermal stress induced by high temperature in cutting zone (up to 10900 C) does not make any significant changes in Tensile Strength property of testing steel at given dimensions. Strain appears, and makes significant deformation of testing elements, when stress rises close to $600 \mathrm{MPa}$, but dynamics and character of the Strain deformations for both of testing specimens the same and almost identical.

\section{REFERENCES}

[1] M.C. Shaw, "Metal Cutting Principles", Oxford University Press, New York, (1984)

[2] Ashby MF, Jones DRH (1998) "Engineering Materials 2". Butterworth. London.

[3] Carvalho SR, Lima e Silva SMM, Machado AR, Guimaraes G (2006) "Temperature Determination at the Chip-Tool Interface using an inverse Thermal Model Considering the Tool and the Tool Holder". Journal of Material Processing Technology 179: 97104

[4] Komanduri R and Hou Z B (2001) "Thermal modeling of the metal cutting process, Part 2: 
ISSN (online): 2581-3048

Volume 4, Issue 11, pp 1-10, November-2020 https://doi.org/10.47001/IRJIET/2020.411001

temperature rise distribution due to frictional heat source at the tool-chip interface". Int J Mech Sci 43: 57-88

[5] Lazoglu I, Altintas Y (2002) "Prediction of tool chip temperature in continuous and interrupted machining". Int J Mach Tools Manuf 42: 1011-1022

[6] Pavel R, Srivastava A (2007) “An experimental investigation of temperatures during conventional and CBN grinding". Int J Adv Manuf Technol 33:412-418

[7] Wang SB, Kou HS (2006) "Selections of working conditions for creep feed grinding. Part (II): workpiece temperature and critical grinding energy for burning". Int J Adv Manuf Technol 28(1-2):3844

[8] Hae-Ji Kim, Nam-Kyung Kim, Jae-Seob Kwak. "Heat flux distribution model by sequential algorithm of inverse heat transfer for determining workpiece temperature in creep feed grinding:". International Journal of Machine Tools \& Manufacture 46 (2006) 2086-2093

[9] Stephenson DA, Ali A (1992) "Tool temperatures in interrupted metal cutting, Transactions of ASME". Journal of Engineering for Industry 114: 127-136

[10] Frederic Winslow Taylor (1907) "On the art of cutting metals". American society of mechanical engineers.

[11] Malkin, S., "Grinding of metals: theory and application," J, of Appl Metalwork 3:95-109, 1984.

[12] Shaw, M.C., "Grinding temperatures", Proceedings of the 12th North American Research Conference 304-308, 1984.

[13] Pavel, R. and Srivastava, A., "An experimental investigation of temperatures during conventional and CBN grinding," Int J Adv Manuf Technol 33:412-418, 2007.

[14] Chandrasekar, S., Shaw, M.,C. and Bhushan, B., "Comparison of grind- ing and lapping of ferrite and metals," Trans ASME J Eng Ind 109:76- 83, 1987.

[15] Green, D.,J., Lange, F.,F.and James, M.,R., "Factors influencing residual stresses due to stress-induced phase transformation," J Amer Ceram Soc 66(9):623629, 1983.

[16] Marshall, D.,B., Evans, A.,G., Khuri-Yakub, B.,T., Tien, J.W. and Kino, G.,S., "The nature of machining damage in brittle materials," Proc Roy Soc London 385:461-475, 1983.

[17] Wang, S.,B. and Kou, H.,S., "Selections of working conditions for creep feed grinding. Part (II): workpiece temperature and critical grinding energy for burning," Int J Adv Manuf Technol 28(1-2):3844, 2006.

[18] King, R.,l. and Hahn, R.,S., "Modern Grinding Technology," Chapman and Hall, New York, London, 1986.

[19] Jaeger, J., C., "Moving Sources of Heat and the Temperature at Sliding Contacts," Proc.R. Soc. New South Wales, 76/3: 203-224, 1942.

[20] Carslaw, H. and Jaeger, J., C., "Conduction of heat in solids", Oxford Science Publications, Oxford University Press, 1959.

[21] Hae-Ji, Kim, Nam-Kyung Kim and Jae-Seob Kwak. "Heat flux distribution model by sequential algorithm of inverse heat transfer for determining workpiece temperature in creep feed grinding." International Journal of Machine Tools \& Manufacture 46, 20862093, 2006.

[22] Rowe, W.,B., Black, B., Mills, H.,S. and Morgan, M.,N., "Experimental investigation of heat transfer in grinding," Ann. CIRP 44 (1), 329-332, 1995.

[23] K.K. Hong, K.,K., and Lo, C.,Y., "An inverse analysis for the heat conduction during a grinding process," Journal of Materials Processing Technology 105, 87-94, 2000.

[24] C. Guo, Wu,Y., Varghese,V. and Malkin.S., "Temperatures and Energy Partition for Grinding with Vitrified CBN Wheels," CIRP Annals Manufacturing Technology, (48): 247-250, 1999.

[25] Malkin, S. and Guo, C., "Thermal Analysis of Grinding." Annals of the CIRP Vol. 56/2: 760-782, 2007.

[26] Trigger, K., J., and Chao, B., T., "An Analytical Evaluation of Metal Cutting Temperatures," Trans. ASME, 73:57-64, 1951.

[27] Malkin, S., "Thermal Aspects of Grinding Part 2 Surface Temperatures and Workpiece Burn", ASME Journal of Engineering for Industry, 96:184- 1191, 1974.

[28] Takazawa, K., "Effects of Grinding Variables on Surface Structure of Hardened Steels," Bull. Japan Soc. Prec. Engg., 2:19-21, 1966.

[29] Fedoseev, O., B. and Malkin, S., "Analysis of Tempering and Rehardening for Grinding of Hardened Steels," ASME Journal of Engineering for Industry, 113:388-394, 1991.

[30] Longbottom JM, Lanham JD (2009) “Cutting temperature measurement while machining - a review". University of the West of England. Bristol. UK. 


\section{Citation of this Article:}

Shehret Tilvaldyev, Julio César Cuéllar Mata, Manuel Alejandro Lira Martinez, Jose Omar Davalos Ramirez, "Experimental Evaluation of the Influence of Overheating on the Properties of Metal During its Processing on Metal-cutting Machines for Subsequent use in Aeronautics" Published in International Research Journal of Innovations in Engineering and Technology IRJIET, Volume 4, Issue 11, pp 1-10, November 2020. https://doi.org/10.47001/IRJIET/2020.411001 